\title{
Hydrological modelling of a slope covered with shallow pyroclastic deposits from field monitoring data
}

\author{
R. Greco ${ }^{1}$, L. Comegna ${ }^{1}$, E. Damiano ${ }^{1}$, A. Guida ${ }^{1,2}$, L. Olivares $^{1}$, and L. Picarelli ${ }^{1}$ \\ ${ }^{1}$ Dipartimento di Ingegneria Civile Design Edilizia e Ambiente, Seconda Università di Napoli, via Roma 29, \\ 81031 Aversa (CE), Italy \\ ${ }^{2}$ Centro Euro-Mediterraneo sui Cambiamenti Climatici, via Maiorise, Capua (CE) 81043, Italy
}

Correspondence to: R. Greco (roberto.greco@unina2.it)

Received: 24 April 2013 - Published in Hydrol. Earth Syst. Sci. Discuss.: 7 May 2013

Revised: 31 July 2013 - Accepted: 4 September 2013 - Published: 16 October 2013

\begin{abstract}
A one-dimensional hydrological model of a slope covered with pyroclastic materials is proposed. The soil cover is constituted by layers of loose volcanic ashes and pumices, with a total thickness between $1.8 \mathrm{~m}$ and $2.5 \mathrm{~m}$, lying upon a fractured limestone bedrock. The mean inclination of the slope is around $40^{\circ}$, slightly larger than the friction angle of the ashes. Thus, the equilibrium of the slope, significantly affected by the cohesive contribution exerted by soil suction in unsaturated conditions, may be altered by rainfall infiltration. The model assumes a single homogeneous soil layer occupying the entire depth of the cover, and takes into account seasonally variable canopy interception of precipitation and root water uptake by vegetation, mainly constituted by deciduous chestnut woods with a dense underbrush growing during late spring and summer. The bottom boundary condition links water potential at the soil-bedrock interface with the fluctuations of the water table of the aquifer located in the fractured limestone, which is conceptually modelled as a linear reservoir. Most of the model parameters have been assigned according to literature indications or from experimental data. Soil suction and water content data measured between 1 January 2011 and 20 July 2011 at a monitoring station installed along the slope allowed the remaining parameters to be identified. The calibrated model, which reproduced very closely the data of the calibration set, has been applied to the simulation of the hydrological response of the slope to the hourly precipitation record of 1999 , when a large flow-like landslide was triggered close to the monitored location. The simulation results show that the lowest soil suction ever attained occurred just at the time the landslide was triggered, indicating that the model is capable of predicting slope failure conditions.
\end{abstract}

\section{Introduction}

Large areas of the Apennines of Campania (southern Italy) are characterised by slopes covered with few meters of loose pyroclastic deposits upon a fractured carbonate bedrock, in which karst aquifers are often located, drained by either perennial or temporary springs (Celico et al., 2006; Petrella et al., 2007, 2009). The equilibrium of such deposits is strongly affected by pore water pressure: in gentle slopes, with a slope angle smaller than the friction angle of the soil material $\left(\varphi^{\prime}\right)$ the increment of positive pore water pressure causes the reduction of the effective stress, which may lead to the failure of the slope; in steep slopes, with inclination comparable or higher than $\varphi^{\prime}$, the equilibrium is possible in unsaturated conditions, thanks to the cohesive action between particles exerted by soil suction, which, after soil wetting, may drop until the triggering of a landslide.

Shallow landslides involving the unsaturated pyroclastic covers of the slopes of the Apennines of Campania are extremely fast and sudden, and warning signs, such as small movements and/or formation of cracks, usually occur a short time before the failure. These features make them among the most worrisome and unpredictable natural hazards.

Clearly, rainfall is the main cause of such landslides, but the actual achievement of the triggering conditions is strongly influenced by other concurring factors, such as stratigraphical (Crosta and Dal Negro, 2003) or geometrical discontinuities, that is, road cuts or scarps (Guadagno et al., 2005), and flow concentration caused by slope or bedrock morphology, or by springs at the soil-bedrock interface (Cascini et al., 2008). More generally, the hydraulic conditions at the soil-bedrock interface deeply affect the 
response of the soil cover to rainfall infiltration. Furthermore, also the vegetation cover may play an important role in the hydrological balance of a slope: root water uptake affects water movement through the unsaturated zone of soil (Feddes et al., 1976), and canopy is capable of intercepting a significant amount of precipitation (Muyzlo et al., 2009).

The development of hydrological models of slope response to precipitation, coupled with slope equilibrium models allowing the safety factor to be evaluated (Montgomery and Dietrich, 1994; Rosso et al., 2006; Capparelli and Versace, 2010; Arnone et al., 2011; Netti et al., 2012), is a key point for setting up effective early warning systems, which represent the most promising approach for the mitigation of the resulting diffuse risk. However, still few examples exist of hydrological models used for landslide prediction accounting for the vegetation effects (Ivanov et al., 2008a, b; Nyambayo and Potts, 2010).

Nonetheless, owing to the complexity of the involved hydrological processes and to the scarce availability of monitoring data of natural slopes, empirical criteria for assessing rainfall thresholds are still the most used means to landslide risk management (Versace et al., 2003; Guzzetti et al., 2007).

In this paper, a mathematical model of the hydrological behaviour of the slope of Cervinara, north of Naples, covered with loose volcanic ashes lying upon fractured limestone is proposed. The model, which has been developed on the basis of the data of an automatic monitoring station operating at the slope since 2009, takes into account, in a simplified way, the hydraulic properties of the unsaturated deposit, the effects of the vegetation cover upon the hydraulic conditions of the top soil, and the hydraulic constraint exerted, at the bottom of the soil cover, by the aquifer located within the fractured bedrock. The proposed model allows soil suction and water content to be reproduced, observed at various depths in the pyroclastic cover, during the rainy season (from autumn till early spring), as well as during the dryer and warmer season (from late spring till the end of summer).

\section{Field monitoring at the slope of Cervinara}

The experimental site is located along the northeast slope of Mount Cornito, near the town of Cervinara, about $50 \mathrm{~km}$ northwest of Naples, southern Italy, just besides the location where, in the night between 15 and 16 December 1999, a flow-like landslide was triggered after an intense rain event lasting nearly two days (Olivares and Picarelli, 2003).

The slope, at an elevation between $550 \mathrm{~m}$ and $760 \mathrm{~m}$ above sea level, has an average inclination of $40^{\circ}$, locally reaching $50^{\circ}$, and the pyroclastic cover, with a slightly variable thickness between 1.8 and $2.5 \mathrm{~m}$, consists of an alternation of loose volcanic ashes, with porosity ranging between 0.68 and 0.75 , and pumices lying upon a fractured limestone bedrock. Such cover is the result of the deposition of materials originating from several eruptions of the two main volcanic complexes of Campania (the Somma-Vesuvius and the Phlegrean Fields) occurred during the last $40000 \mathrm{yr}$ (Rolandi et al., 2003; Di Crescenzo and Santo, 2005). Under the organic rich topsoil of volcanic ashes (up to $60 \mathrm{~cm}$ of thickness), the following layers are usually found (Olivares and Picarelli, 2003; Damiano et al., 2012): coarse pumices (A), with maximum thickness of around $40 \mathrm{~cm}$, sometimes not found owing to erosive processes which occurred during the volcanic resting phases; volcanic ashes (B), with thickness ranging between $100 \mathrm{~cm}$ and $160 \mathrm{~cm}$; fine pumices mixed with ashes (C), $30-60 \mathrm{~cm}$ thick (such a layer is in some cases hardly distinguishable from layer C); altered ashes (D), $20-80 \mathrm{~cm}$ thick, which covers the fractured calcareous bedrock. Examples of the layered soil cover observed along the slope are given in Fig. 1. Table 1 summarises some of the main physical characteristics of the soils.

Visual inspection in trenches showed that roots are found within the entire soil depth, with a maximum density in the upper $0.40 \mathrm{~m}$, becoming sparse below $1.50 \mathrm{~m}$ depth.

The slope is covered with woods, mainly deciduous chestnuts (Castanea sativa) with few deciduous beeches (Fagus sylvatica). From May to late September, when the foliage of the trees is present, a dense underbrush grows, mainly formed by ferns (Pteridium aquilinum) and other seasonal shrubs. Few areas at the upper part of the slope are not covered with woods and the vegetation consists of shrubs (Cytisus scoparius) and grass (Festuco Brometea).

Except during rare extremely intense rainfall events, there is no evidence of the occurrence of significant surface runoff.

In August 2009 an automatic hydrological monitoring station at high temporal resolution was installed. Since then, measurements of volumetric water content by time domain reflectometry (TDR) and capillary tension by jet-fill tensiometers have been acquired every two hours. In addition, a rain gauge for hourly automatic acquisition has been installed, with sensitivity to rainfall height increments of $0.2 \mathrm{~mm}$. The monitoring station includes six tensiometers and five TDR metallic probes placed at various depths between $0.30 \mathrm{~m}$ and $1.70 \mathrm{~m}$ and grouped into two nests of sensors located $5 \mathrm{~m}$ apart from each other. The TDR probes are connected through coaxial cables and a multiplexer to a Campbell Scientific Inc. TDR-100 reflectometer. Most of the probes were placed in the immediate proximity of the ceramic tips of the tensiometers, as to allow for coupling water content and capillary tension measured at the same depths.

The TDR measurements are carried out by means of a specific calibration relationship, linking soil water content with bulk dielectric permittivity, which has been experimentally determined over undisturbed samples of the investigated soil (Greco et al., 2010). The obtained relationship is quite similar to analogous relationships found in literature for similar volcanic soils (Regalado et al., 2003).

For the automatic acquisition and storage of the monitoring data, all the installed equipment is connected to a Campbell Scientific Inc. CR-1000 data logger, and powered by a 


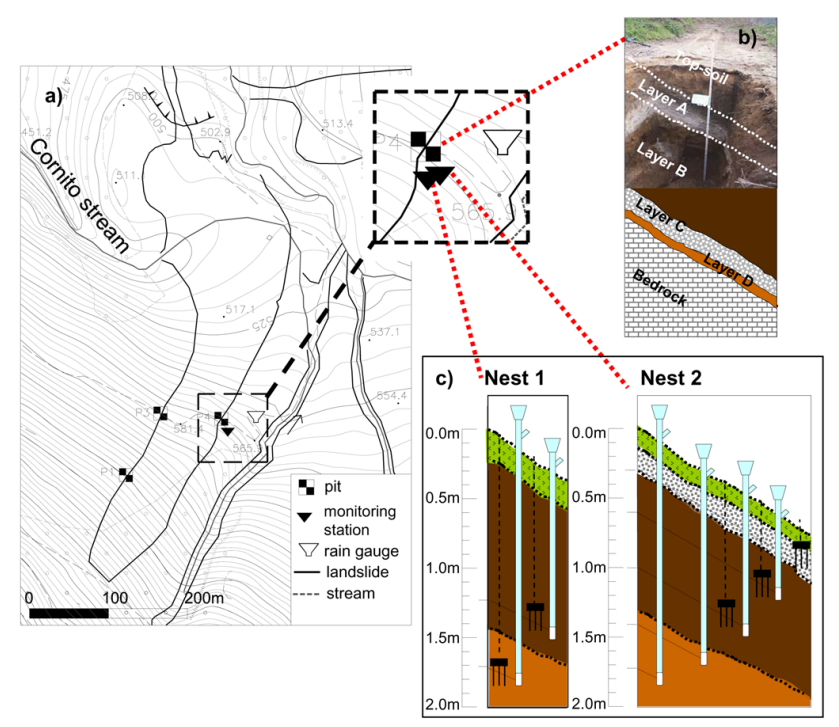

Fig. 1. The instrumented slope of Cervinara: (a) plan view with indication of the monitoring station and of the 1999 landslide limit; (b) an example of the layered profile of the soil cover as found in a pit close to the monitoring station; (c) sketch of the installed instruments and of the soil profile at the field monitoring station.

Table 1. Main physical properties of the soils constituting the cover: $c^{\prime}$ - effective cohesion; $\varphi^{\prime}-$ effective friction angle; $\gamma_{s}-$ specific unit weight.

\begin{tabular}{llrrrl}
\hline Layer & Material & $\begin{array}{r}c^{\prime} \\
(\mathrm{kPa})\end{array}$ & $\begin{array}{r}\varphi^{\prime} \\
\left(^{\circ}\right)\end{array}$ & $\begin{array}{r}\gamma_{\mathrm{s}} \\
\left(\mathrm{kN} \mathrm{m}^{-3}\right)\end{array}$ & $\begin{array}{l}\text { Porosity } \\
(\%)\end{array}$ \\
\hline A & coarse pumices & 0 & 45 & 23 & $50-55$ \\
$\mathrm{~B}$ & volcanic ashes & 0 & 38 & 26.5 & $68-75$ \\
$\mathrm{C}$ & ashes with pumices & 0 & 40 & 26 & $50-70$ \\
$\mathrm{D}$ & altered ashes & 2 & 38 & 26.5 & 60 \\
\hline
\end{tabular}

$12 \mathrm{~V}$ battery connected to a solar panel. The location of the monitoring station is given in Fig. 1a, together with a sketch of the positions of the various installed sensors (Fig. 1c).

Figure 2 shows soil suction head and volumetric water content measured at four depths between 1 January 2011 and 20 July 2011, together with the corresponding daily hyetograph. The plotted soil suction and water content trends look similar to those observed in other years at the same site, and are substantially in agreement with what has been reported for other pyroclastic slopes in Campania (Cascini et al., 2013). After the heaviest rainfall events occurred during winter and early spring, soil suction head, especially at the shallowest tensiometer, dropped to less than $0.2 \mathrm{~m}$. Nonetheless, the soil was always far from saturation, as indicated by the water content, rarely exceeding 0.40 .

During the rainy months (from January to April), the fluctuations of soil suction and water content caused by rainfall infiltration tended to be smoothened and delayed at increasing depth. The soil suction measured by the uppermost

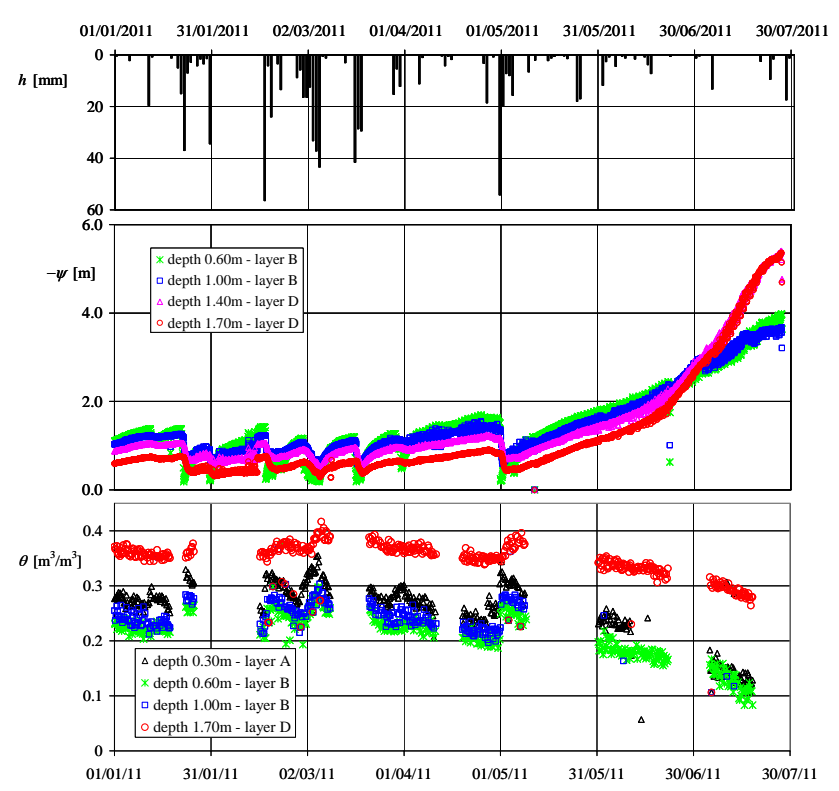

Fig. 2. Field monitoring data observed at various depths between 1 January 2011 and 20 July 2011. From top to bottom: daily rainfall height; soil suction; soil volumetric water content.

tensiometer, quickly decreasing during and immediately after rainfall, always returned to be the highest of the entire soil profile within 24 to $48 \mathrm{~h}$ after the rainfall. This behaviour indicates that along the layered profile there is no obstacle to the downward propagation of the infiltration flux, as confirmed by the measured water content, never attaining high values at the shallowest investigated depths. The observed behaviour is therefore significantly different from what has been observed in other similar layered pyroclastic slopes of Campania, such as Pizzo d'Alvano, where the presence of layers of coarse pumices below the ashes, owing to the great downward decrease of hydraulic conductivity, caused the formation of a capillary barrier (Mancarella and Simeone, 2012; Mancarella et al., 2012). The absence of the capillary barrier effect at the investigated slope can be ascribed to the fact that the coarser pumices (layer A) are found at the top of the soil profile, while the texture of layer $\mathrm{C}$ (a mixture of ashes and fine pumices), where present, is not so different from that of the overlying layer B.

During late spring and summer, soil suction increased at all depths. Such increment does not seem to be caused only by upward evapotranspiration fluxes. In fact, the two deepest tensiometers measured the steepest increasing trend of suction (Fig. 2), which indicates a downward-directed drainage, while the two upper TDR probes, buried at $-0.30 \mathrm{~m}$ and $-0.60 \mathrm{~m}$, showed a decreasing trend of water content higher than the others (the volumetric water content at those depths dropped from 0.33 to 0.13 and from 0.26 to 0.08 between 1 May 2011 and 20 July 2011), which may be interpreted as 
the effect of evapotranspiration affecting only the upper part of the soil cover.

Therefore, most of the summer drainage of the soil cover is likely related to the decrease of the water level in the underlying aquifer located in the fractured bedrock, as it has been reported to occur typically in similar contexts during the dry season (Petrella et al., 2007, 2009). Such interpretation is confirmed by Fig. 3, in which the vertical water potential gradients, observed at three depths during the same period, are plotted. The gradients have been obtained by the differences between the water potential provided by the suction measured by tensiometers buried at adjacent depths. The estimated gradients always resulted positive, indicating that vertical water flux was always directed downward towards the fractured bedrock. During winter and early spring, the water potential gradient was always $<1$ at all depths (except during or immediately after rainfall events), indicating that the capillarity gradient, owing to the increasing soil moisture with depth, tended to impede the downward-directed gravitydriven flow. Conversely, during summer the water potential gradient grew, becoming $>1$ in the upper part of the profile by the end of June, indicating that capillarity summed its action to gravity, enhancing the downward flow towards the bottom of the profile. In July, the vertical gradient at the lowest depths kept on increasing, indicating leakage from the soil cover towards the underlying fractured bedrock. In the upper layer, instead, the gradient constantly decreased, becoming $<1$ after mid-July. This can be explained as an effect of the upward evapotranspiration from the top soil layer, which was maximum during that period.

It is therefore clear, from the analysis of Figs. 2 and 3, that the bottom boundary condition strongly affects the suction profile along the soil cover: in fact, the establishment of the necessary hydraulic gradients allowing the infiltration fluxes to pass through the soil cover, which depends on the unsaturated hydraulic conductivity at the various depths, may lead the soil to approach saturated conditions only if the capillary pressure at the bottom of the soil cover is high enough. The monitoring results suggest that, at the beginning of a rainfall event, soil water potential at the interface with the bedrock may be related to the water level in the aquifer located inside the fractured calcareous bedrock formation, rather than to the precipitation fallen before the considered rainfall event.

Another feature of the field monitoring is that in most cases the precipitation events occurring after April hardly affected suction and water content measured at any depth; conversely, soil suction was affected by rainfall events of similar characteristics occurring before May, even when the soil at the beginning of the precipitation presented similar suction values.

In particular, the seasonally variable response to precipitations seems clearly related to the seasonal variations of vegetation cover. Indeed, canopy interception capacity of precipitation is the sum of the contributions of tree foliage and underbrush. In woods of deciduous trees, the first contribution

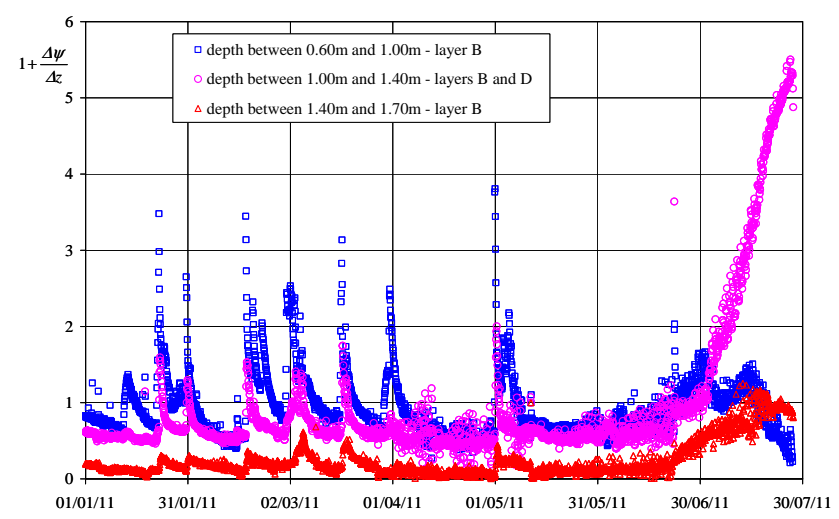

Fig. 3. Soil water potential vertical gradients estimated from field measurements.

is obviously strongly related to the presence of leaves, with reported values of up to $6.0 \mathrm{~mm}$ during summer (Breuer et al., 2003), while the second is also expected to show seasonality, owing to the seasonal growth of the brushwood. Furthermore, the evapotranspiration is deeply affected by the seasonal cycle of vegetation, which sums its action to the seasonally variable climatic constraints (Herbst et al., 2008).

By coupling soil water content and suction head data measured with sensors buried at the same depths, plotted in Fig. 4, it has been possible to estimate the water retention curve exhibited by the soil in the field. The experimental points clearly indicate that, between $-0.60 \mathrm{~m}$ and $-1.20 \mathrm{~m}$, it is possible to consider the soil as homogeneous (layer B). Conversely, at $-1.70 \mathrm{~m}$ the water retention data show the behaviour of a finer textured soil. Such a result is consistent with the reported behaviour of the altered ashes of layer D found in slopes near Cervinara (Sorbino and Nicotera, 2013).

\section{The hydrological model}

Despite the layered nature of the soil cover of the investigated slope, the proposed model attempts to simulate its hydrological behaviour by means of a single homogeneous soil layer. As a consequence, the hydraulic properties of the soil constituting such a layer should be regarded as "effective" properties, useful for reliably reproducing the observed phenomena, rather than as being the actual properties of the soils belonging to the investigated profile.

Such a simplified approach has been chosen for the following reasons: (i) the layered profile is extremely variable, even along the same slope (see Fig. 1), because the various layers deposited by different eruptions have been subjected to alteration, weathering, and in some cases erosion; (ii) the hydraulic characterisation of pumices is quite difficult, as it is impossible to take undisturbed samples of such soils; (iii) too much information is needed for the complete hydraulic characterisation of even a single soil profile at a point of a 


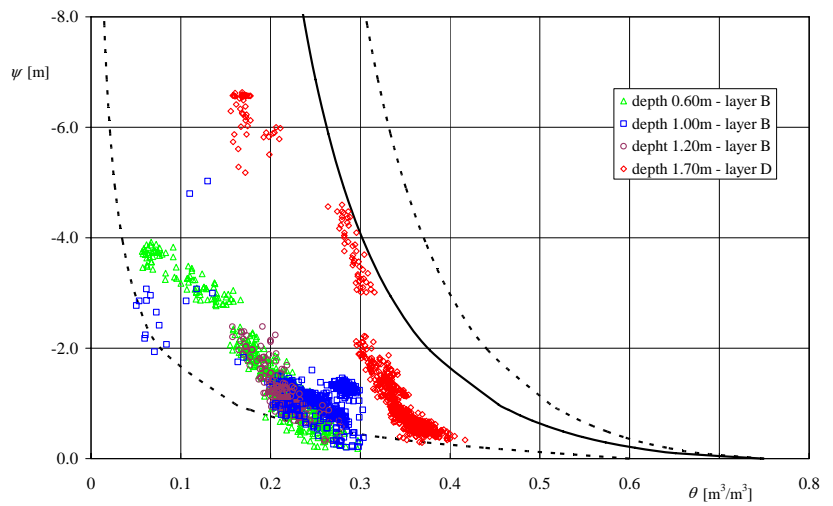

Fig. 4. Water retention of the investigated soil: dots represent field experimental data at various depths; the bold line is the calibrated water retention curve of the assumed single homogeneous layer; the dashed lines represent the limits of the range of water retention curves considered in the calibration procedure.

slope, hampering the practical usefulness of more sophisticated models.

Therefore, as it will be better explained in the following sections, the proposed model has been built up as suggested by the data collected during the monitoring activities. The values of soil water content and suction observed at the two instrumented locations indicate that in unsaturated conditions there are no significant differences in water potential at the same depth in different points of the slope. Thus, the gradients of all the variables along the plane parallel to the slope are negligible, and it is possible to adopt a 1-D vertical model.

As a consequence, the model consists of the classical 1-D Darcy-Buckingham motion equation along the vertical direction $z[\mathrm{~m}]$, positive upward, coupled with the water mass balance equation:

$$
v=-k(\theta) \frac{\partial}{\partial z}[z+\psi(\theta)]=-k(\theta)\left[1+\frac{\partial \psi(\theta)}{\partial z}\right],
$$

$$
\frac{\partial \theta}{\partial t}=-\frac{\partial v}{\partial z}-q_{\mathrm{r}}
$$

In Eqs. (1) and (2) $v\left[\mathrm{~m} \mathrm{~s}^{-1}\right]$ represents the unit vertical water flux; $\psi[\mathrm{m}]$ is the capillary pressure head; $\theta$ is the volumetric water content of soil; $k\left[\mathrm{~m} \mathrm{~s}^{-1}\right]$ is the hydraulic conductivity of unsaturated soil; $q_{\mathrm{r}}\left[\mathrm{s}^{-1}\right]$ is the rate of water uptake by roots per unit volume of soil.

The two equations are combined obtaining the Richards equation with a root water uptake term:

$$
\frac{\mathrm{d} \theta}{\mathrm{d} \psi} \frac{\partial \psi}{\partial t}=\frac{\mathrm{d} k}{\mathrm{~d} \theta} \frac{\mathrm{d} \theta}{\mathrm{d} \psi} \frac{\partial \psi}{\partial z}+\frac{\partial}{\partial z}\left(k \frac{\partial \psi}{\partial z}\right)-q_{\mathrm{r}}
$$

To take into account the observed reduction of root density with depth, the root water uptake $q_{\mathrm{r}}$ has been modelled by linearly distributing along the root depth, $d_{\mathrm{r}}[\mathrm{m}]$, the total evapotranspiration flux (Nyambayo and Potts, 2010):

$$
\begin{array}{cc}
-d_{\mathrm{r}} \leq z \leq 0 & q_{\mathrm{r}}=\frac{2 \kappa(\psi) E_{\mathrm{p}}}{d_{\mathrm{r}}}\left(1+\frac{z}{d_{\mathrm{r}}}\right) \\
z<-d_{\mathrm{r}} & q_{\mathrm{r}}=0
\end{array}
$$

In Eq. (4), the potential evapotranspiration $E_{\mathrm{p}}\left[\mathrm{m} \mathrm{s}^{-1}\right]$ is evaluated by means of the Penman-Monteith equation (Shuttleworth, 1993):

$E_{\mathrm{p}}=\frac{1}{\lambda}\left[\frac{\Delta A+\rho_{\mathrm{a}} c_{p} \frac{(1-\varphi) p_{\mathrm{vs}}}{r_{a}}}{\Delta+\gamma\left(1+\frac{r_{s}}{r_{a}}\right)}\right]$.

In Eq. (5), $\lambda\left[\mathrm{J} \mathrm{m}^{-3} \mathrm{~Pa} \mathrm{~K}^{-1}\right]$ is the latent heat of vaporisation of water; $\rho_{\mathrm{a}}\left[\mathrm{kg} \mathrm{m}^{-3}\right]$ is the density of moist air; $c_{p}=1013 \mathrm{~J} \mathrm{~kg}^{-1} \mathrm{~K}^{-1}$ is the specific heat of moist air; $\varphi$ is air relative humidity; $p_{\mathrm{vs}}[\mathrm{Pa}]$ is the saturated vapor pressure; $\gamma\left[\mathrm{Pa} \mathrm{K}^{-1}\right]$ is the psychrometric constant; $\Delta\left[\mathrm{Pa} \mathrm{K}^{-1}\right]$ is the derivative of $p_{\mathrm{vs}}$ with respect to air temperature; $A\left[\mathrm{~W} \mathrm{~m}^{-2}\right]$ is the available energy per unit time; $r_{\mathrm{a}}\left[\mathrm{s} \mathrm{m}^{-1}\right]$ is the aerodynamic resistance to upward vapor diffusion; and $r_{\mathrm{s}}\left[\mathrm{s} \mathrm{m}^{-1}\right]$ is the surface resistance to vapor emission by the stomata of leaves.

The quantities $\lambda, p_{\mathrm{vs}}$ and $\Delta$ depend on air temperature; $\gamma$ and $\rho_{\mathrm{a}}$ depend also on atmospheric pressure. The energy per unit time available for evaporation has been assumed equal to $95 \%$ of the total net radiation $R_{\mathrm{n}}$ :

$$
R_{\mathrm{n}}=S_{\mathrm{n}}+L_{\mathrm{n}} \begin{gathered}
S_{\mathrm{n}}=(1-\alpha) S_{0} f_{\mathrm{c}} \\
L_{\mathrm{n}}=\sigma f_{\mathrm{c}}\left(0.27 \sqrt{\varphi p_{\mathrm{vs}}}-0.53\right) T_{\mathrm{a}}^{4} f_{\mathrm{c}}=0.25+0.50 \frac{n_{\mathrm{c}}}{24}
\end{gathered}
$$

In Eq. (6), $S_{0}=240 \mathrm{~W} \mathrm{~m}^{-2}$ represents the extraterrestrial solar radiation; $\sigma=5.675 \times 10^{-8} \mathrm{~W} \mathrm{~m}^{-2}$ is the StefanBoltzmann constant; $f_{\mathrm{c}}$ is the cloud cover factor, depending on the daily number of hours with clear sky, $n_{\mathrm{c}} ; T_{\mathrm{a}}[\mathrm{K}]$ is the absolute temperature of air; $\alpha$ is the short-wave radiation reflection coefficient (albedo), depending on the vegetation type.

The following expression for the resistance $r_{\mathrm{a}}$ has been assumed:

$r_{\mathrm{a}}=\frac{\ln \left[\frac{\left(z_{u}-0.67 h_{\mathrm{c}}\right)}{0.123 h_{\mathrm{c}}}\right]^{2}}{0.168 U_{z}}$.

In Eq. (7), $U_{z}\left[\mathrm{~m} \mathrm{~s}^{-1}\right]$ represents the speed of wind measured at elevation $z_{u}[\mathrm{~m}]$ above soil surface; $h_{\mathrm{c}}[\mathrm{m}]$ is vegetation height.

The function $\kappa(\psi)$ in Eq. (4), accounting for the dependence on capillary pressure head of the effective water uptake by roots, is here modelled as in Feddes et al. (1976):

$$
\begin{gathered}
\psi>\psi_{1} \quad \kappa=0 \\
\psi_{1} \geq \psi>\psi_{2} \kappa=\frac{\psi_{1}-\psi}{\psi_{1}-\psi_{2}} \\
\psi_{2} \geq \psi>\psi_{3} \quad \kappa=1 \quad \text { with } \psi_{4}<\psi_{3}<\psi_{2}<\psi_{1} . \\
\psi_{3} \geq \psi>\psi_{4} \kappa=\frac{\psi-\psi_{4}}{\psi_{3}-\psi_{4}} \\
\psi_{4} \geq \psi \quad \kappa=0
\end{gathered}
$$


In Eq. (8), $\psi_{1}$ represents the anaerobiosis point, above which the roots are supposed not to extract water from soil; $\psi_{2}$ and $\psi_{3}$ are the limits of the capillary pressure head range in which the uptake of water by roots is maximum, the first usually assumed equal to the field capacity (Nyambayo and Potts, 2010); $\psi_{4}$ is the permanent wilting point, below which plant roots are not able to extract water from soil.

The hydraulic behaviour of the soil is described by introducing, in Eq. (3), appropriate expressions for the water retention curve $\psi(\theta)$ and for the hydraulic conductivity function $k(\theta)$. In the proposed model, they are described with the expressions proposed by Van Genuchten (1980) and Brooks and Corey (1964), respectively:

$$
\begin{aligned}
& \frac{\theta-\theta_{\text {res }}}{\theta_{\text {sat }}-\theta_{\text {res }}}=\frac{1}{\left[1+\left(\alpha_{\mathrm{VG}}|\psi|\right)^{n}\right]^{m}}, \\
& k=k_{\text {sat }}\left(\frac{\theta-\theta_{\text {res }}}{\theta_{\text {sat }}-\theta_{\text {res }}}\right)^{\delta} .
\end{aligned}
$$

Therefore, for the hydraulic characterisation of the unsaturated soil, the adopted expressions require the assignment of appropriate values to seven parameters: $\theta_{\text {sat }}$, the volumetric water content of the soil at saturation; $\theta_{\text {res }}$, the residual water content of the soil; $k_{\mathrm{sat}}\left[\mathrm{m} \mathrm{s}^{-1}\right]$, the hydraulic conductivity of the soil at saturation; $\alpha_{\mathrm{VG}}\left[\mathrm{m}^{-1}\right], n, m$, and $\delta$, shape parameters related with the pore size distribution of the soil.

Equation (3) must be completed with initial and boundary conditions. The initial condition is an assigned distribution of capillary pressure head within the soil profile to be modelled. The boundary conditions have to be assigned at soil surface and at the soil-bedrock interface.

In the proposed model, the following boundary condition is written at soil surface $(z=0)$, expressing the water balance in a layer of depth $d z$ just below the soil surface:

$$
\begin{aligned}
& \left.\frac{\mathrm{d} \theta}{\mathrm{d} \psi} \frac{\partial \psi}{\partial t}\right|_{z=-d z / 2} d z \\
& \quad=i_{z=0}+k_{z=-d z}\left(1+\left.\frac{\partial \psi}{\partial z}\right|_{z=-d z / 2}\right)-q_{\mathrm{r}, z=-d z} d z
\end{aligned}
$$

In Eq. (11) $i_{z=0}$ represents the water infiltrating through the soil surface, which is:

$$
\left\{\begin{array}{l}
\left.R-\frac{\mathrm{d} I}{\mathrm{~d} t}\right)<i_{\mathrm{p}} \Rightarrow i_{z=0}=R-\frac{\mathrm{d} I}{\mathrm{~d} t} \\
\left.R-\frac{\mathrm{d} I}{\mathrm{~d} t}\right) \geq i_{\mathrm{p}} \Rightarrow \quad i_{z=0}=i_{\mathrm{p}}
\end{array} \text { with } i_{\mathrm{p}}=k_{z=0}\left(1+\left.\frac{\partial \psi}{\partial z}\right|_{z=0}\right) .\right.
$$

In Eq. (12) $R\left[\mathrm{~m} \mathrm{~s}^{-1}\right]$ is rainfall intensity; $I[\mathrm{~m}]$ is the rainfall height intercepted by vegetation per unit horizontal surface; $i_{\mathrm{p}}\left[\mathrm{m} \mathrm{s}^{-1}\right]$ is potential infiltration rate. The interception rate $\mathrm{d} I / \mathrm{d} t$ is assumed equal to $R$ until the maximum interception capacity $I_{\max }[\mathrm{m}]$ is attained. Afterwards, $\mathrm{d} I / \mathrm{d} t$ is set to zero until rain ends.

The bottom boundary condition assumes $\psi_{\mathrm{b}}$, the capillary pressure head at the soil-bedrock interface $\left(z=z_{\mathrm{b}}\right)$, to follow the fluctuations of the water table of the underlying aquifer, located in the fractured calcareous rocks. Thus, in the water mass balance equation of the unit horizontal surface of the aquifer, which is schematized with a linear reservoir model, the derivative of $\psi_{\mathrm{b}}$ with respect to time can substitute that of the water table level $h_{\mathrm{a}}=\psi_{\mathrm{b}}+z_{\mathrm{b}}-z_{0}$, leading to the bottom boundary condition:

$$
\begin{aligned}
& n_{\mathrm{a}} \frac{\mathrm{d} h_{\mathrm{a}}}{\mathrm{d} t}=i_{\mathrm{b}}-q_{\mathrm{s}}=i_{\mathrm{b}}-\frac{h_{\mathrm{a}}}{K_{\mathrm{a}}} \Rightarrow \\
& \quad n_{\mathrm{a}} \frac{d \psi_{\mathrm{b}}}{\mathrm{d} t}=k_{z=z_{\mathrm{b}}}\left(1+\left.\frac{\partial \psi}{\partial z}\right|_{z=z_{\mathrm{b}}}\right)-\frac{\psi_{\mathrm{b}}+z_{\mathrm{b}}-z_{0}}{K_{\mathrm{a}}} .
\end{aligned}
$$

In Eq. (13) $n_{\mathrm{a}}$ is the effective porosity of the calcareous fractured bedrock; $i_{\mathrm{b}}\left[\mathrm{m} \mathrm{s}^{-1}\right]$ is the vertical infiltration through the soil-bedrock interface; $q_{\mathrm{s}}\left[\mathrm{m} \mathrm{s}^{-1}\right]$ is the discharge of the spring draining a unit horizontal surface of the aquifer; $K_{\mathrm{a}}$ [s] is the time constant of the linear reservoir model of the aquifer; $z_{0}$ is the elevation of the aquifer bed (when $\psi_{\mathrm{b}}=-\left(z_{\mathrm{b}}-z_{0}\right)$, it results $\left.q_{\mathrm{s}}=0\right)$.

\section{Estimation of model parameters}

The application of the above described model requires the assignment of values to 27 parameters, summarised in Table 2, where also the adopted value and the followed estimation method are indicated. Most of the parameters have been assigned on the basis of literature and/or experimental evidence, while only 10 have been identified by means of model calibration against soil suction data provided by the monitoring activity carried out between 1 January 2011 and 20 July 2011. The identification of such parameters has been made by minimizing the sum of the squared differences between measured and estimated soil suctions at the depths of $-0.60 \mathrm{~m},-1.00 \mathrm{~m},-1.40 \mathrm{~m}$ and $-1.60 \mathrm{~m}$, carried out by means of a genetic algorithm (Goldberg, 1989). Such an evolutionary minimum search technique easily allows the values of the unknown parameters to be constrained. In fact, also for the case of parameters identified through model calibration, the unknown values have been constrained within intervals derived from field observation and/or from available experimental data.

In particular, according to information from undisturbed soil samples, $\theta_{\text {sat }}$ and $\theta_{\text {res }}$ have been constrained within the intervals $[0.6,0.75]$ and $[0,0.05]$, respectively. The other parameters defining the shape of the water retention curve of the assumed single homogeneous soil layer (namely, $\alpha_{\mathrm{VG}}, n$ and $m$ ) have been constrained in such a way that the corresponding water retention curves mapped the part of the $(\psi$, $\theta)$ plane where the experimental data of water content and suction fell (Fig. 4). Also the parameters $k_{\text {sat }}$ and $\delta$ defining, together with $\alpha_{\mathrm{VG}}, n$ and $m$, the hydraulic conductivity curve of the Brooks and Corey model, have been identified through model calibration, by constraining their values within predefined intervals according to available hydraulic conductivity 
Table 2. Summary of model parameters.

\begin{tabular}{|c|c|c|c|c|c|}
\hline Model parameter & & Estimation method & $\begin{array}{l}\text { Lower } \\
\text { limit }\end{array}$ & $\begin{array}{l}\text { Upper } \\
\text { limit }\end{array}$ & $\begin{array}{l}\text { Adopted } \\
\text { value }\end{array}$ \\
\hline \multirow{7}{*}{$\begin{array}{l}\text { Soil hydraulic } \\
\text { characteristics }\end{array}$} & Saturated water content $\theta_{\text {sat }}$ & \multirow[t]{7}{*}{ calibrated } & 0.6 & 0.75 & 0.749 \\
\hline & Residual water content $\theta_{\text {res }}$ & & 0.0 & 0.05 & 0.008 \\
\hline & van Genuchten parameter $\alpha_{\mathrm{VG}}\left(\mathrm{m}^{-1}\right)$ & & 8.0 & 15.0 & 11.78 \\
\hline & van Genuchten parameter $m$ & & 0.5 & 1.1 & 0.676 \\
\hline & van Genuchten parameter $n$ & & 0.7 & 1.2 & 0.683 \\
\hline & Saturated hydraulic conductivity $k_{\text {sat }}\left(\mathrm{m} \mathrm{s}^{-1}\right)$ & & $2.8 \times 10^{-6}$ & $1.7 \times 10^{-4}$ & $8.04 \times 10^{-5}$ \\
\hline & Brooks and Corey exponent $\delta$ & & 3.0 & 6.0 & 5.67 \\
\hline \multirow{10}{*}{$\begin{array}{l}\text { Potential evapo- } \\
\text { transpiration }\end{array}$} & Winter stomatal resistance $r_{\mathrm{a}}\left(\mathrm{s} \mathrm{m}^{-1}\right)$ & \multirow[t]{3}{*}{ assigned (Breuer et al., 2003) } & - & - & 2800 \\
\hline & Summer stomatal resistance $r_{\mathrm{a}}\left(\mathrm{s} \mathrm{m}^{-1}\right)$ & & - & - & 400 \\
\hline & Albedo $\alpha$ & & - & - & 0.25 \\
\hline & Vegetation height $h_{\mathrm{c}}(\mathrm{m})$ & assigned (visual inspection) & - & - & 15.0 \\
\hline & Wind speed $U_{z}\left(\mathrm{~m} \mathrm{~s}^{-1}\right)$ & \multirow[t]{6}{*}{ assigned (mean of meteorological data) } & - & - & 1.0 \\
\hline & Daily hours with clear sky $n_{\mathrm{c}}$ & & - & - & 19 \\
\hline & Monthly max temperature $T_{\max }\left({ }^{\circ} \mathrm{C}\right)$ & & - & - & see Table 2 \\
\hline & Monthly min temperature $T_{\min }\left({ }^{\circ} \mathrm{C}\right)$ & & - & - & see Table 2 \\
\hline & Maximum air relative humidity $\varphi_{\max }$ & & - & - & 0.75 \\
\hline & Minimum air relative humidity $\varphi_{\min }$ & & - & - & 0.40 \\
\hline Canopy & $\begin{array}{l}\text { Winter maximum interception } \\
\text { capacity } I_{\max }(\mathrm{mm})\end{array}$ & assigned (Breuer et al., 2003) & - & - & 1.0 \\
\hline interception & Summer maximum interception capacity $I_{\max }(\mathrm{mm})$ & calibrated & 4.0 & 10.0 & 4.0 \\
\hline \multirow{5}{*}{$\begin{array}{l}\text { Root water } \\
\text { uptake }\end{array}$} & Maximum root depth $d_{\mathrm{r}}(\mathrm{m})$ & assigned (visual inspection) & - & - & 2.4 \\
\hline & Anaerobiosis point $\psi_{1}(\mathrm{~m})$ & assigned (Feddes et al., 1976) & - & - & 0.0 \\
\hline & Field capacity $\psi_{2}(\mathrm{~m})$ & assigned (Nyambayo and Potts, 2010) & - & - & 0.5 \\
\hline & Water potential $\psi_{3}(\mathrm{~m})$ & assigned (Feddes et al., 1976) & - & - & 15.0 \\
\hline & Permanent wilting point $\psi_{4}(\mathrm{~m})$ & & - & - & 150.0 \\
\hline \multirow[t]{3}{*}{ Aquifer linear reservoir } & $\begin{array}{l}\text { Aquifer bed depth below soil- } \\
\text { bedrock interface } z_{\mathrm{b}}-z_{0}(\mathrm{~m})\end{array}$ & calibrated & 5.0 & 10.0 & 7.97 \\
\hline & Aquifer effective porosity $n_{\mathrm{a}}$ & assigned (Worthington and Ford, 2009) & - & - & 0.005 \\
\hline & Aquifer time constant $K_{\mathrm{a}}$ (days) & calibrated & 700 & 1300 & 871 \\
\hline
\end{tabular}

data measured over undisturbed samples taken at the investigated slope (Fig. 5).

The climate parameters needed for the calculation of $E_{\mathrm{p}}$ have been obtained from the $20 \mathrm{yr}$ long data set of the meteorological station of S. Croce del Sannio, located at $700 \mathrm{~m}$ above sea level around $20 \mathrm{~km}$ far from the slope. The wind speed at the height of $2.0 \mathrm{~m}$ above soil surface and the number of hours with clear sky have been assumed constant and equal to their mean values (Table 1). The albedo and the vegetation height have been assigned according to the characteristics of the vegetation cover (Breuer et al., 2003). Monthly maximum and minimum values of $E_{\mathrm{p}}$ have been evaluated by introducing monthly means of maximum and minimum air temperatures into the relevant parameters of Eq. (5). Air relative humidity corresponding to maximum and minimum temperatures has been assumed 0.40 and 0.75 , respectively. The daily variation of $\mathrm{ET}_{\mathrm{p}}$ between the obtained extremes has been assumed sinusoidal, with maximum at 02:00 p.m. LT.

The other parameters related to vegetation have been considered seasonally variable. In particular, the stomatal resistance, $r_{\mathrm{s}}$, has been assumed equal to $400 \mathrm{~s} \mathrm{~m}^{-1}$ between May and September (when foliage and underbrush grow): the value of $625 \mathrm{~s} \mathrm{~m}^{-1}$ for Italian Castanea sativa, reported by Breuer et al. (2003), has been reduced to account for the contribution by underbrush. During the other months, a value of $2800 \mathrm{~s} \mathrm{~m}^{-1}$ has been assumed.

Table 3 gives the monthly minimum and maximum temperatures and the corresponding monthly mean potential evapotranspiration rates.

The maximum interception capacity by canopy, $I_{\max }$, has been assumed equal to $1.0 \mathrm{~mm}$ when trees are leafless (Breuer et al., 2003; Eriksson et al., 2005), while it has been calibrated in the interval $[4.0 \mathrm{~mm}, 10.0 \mathrm{~mm}]$ during the growing season (Table 1).

The maximum root depth, $d_{\mathrm{r}}$, has been assumed equal to the soil cover thickness, consistently with what indicated by visual inspections of the soil profile carried out in trenches. The capillary pressure head parameters $\psi_{1}, \psi_{2}, \psi_{3}$ and $\psi_{4}$, of the root water uptake model have been assigned according to literature indications (Feddes et al., 1976; Nyambayo and Potts, 2010).

The linear reservoir model introduced to simulate the effects of the water table fluctuations upon the water potential at the interface between soil cover and bedrock requires the assignment of three parameters. The effective porosity of the fractured limestone, $n_{\mathrm{a}}$, has been assumed equal to 0.005 according to indications found in literature for carbonate fractured rocks (Worthington and Ford, 2009). The other two parameters, identified through calibration, have 


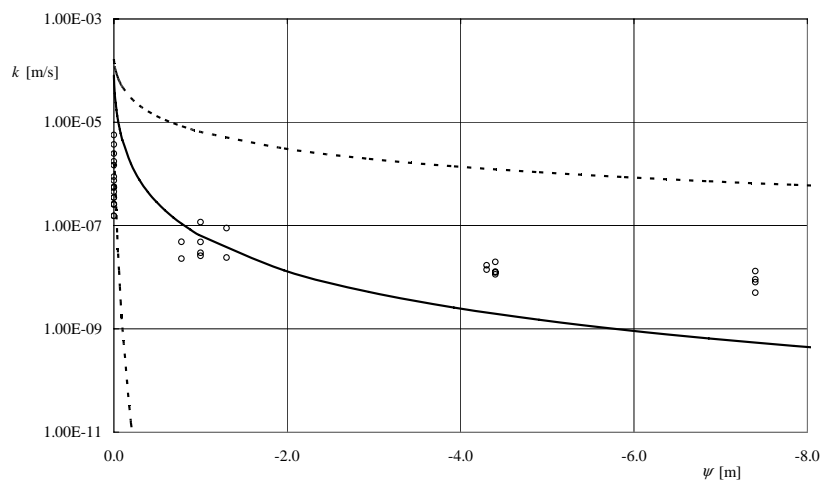

Fig. 5. Hydraulic conductivity curve: dots represent laboratory experimental data over samples of ashes (layer B); the bold line is the calibrated hydraulic conductivity curve of the assumed single homogeneous layer; the dashed lines represent the limits of the range of hydraulic conductivity curves considered in the calibration procedure.

been constrained in such a way to obtain that, with the typical precipitation regime, the total yearly water balance of the aquifer was in equilibrium.

\section{Results and discussion}

Figure 6 shows the comparison between measured and simulated capillary pressure head during the period considered for model calibration. The obtained root mean squared error, expressed in terms of suction head, results equal to $0.244 \mathrm{~m}$, which is not far from the accuracy of the tensiometers, equal to $\pm 0.1 \mathrm{~m}$. For better evaluating the obtained agreement, a detail related to winter and early spring, when the trees are leafless and the underbrush is bare, is given in Fig. 6a, while Fig. $6 \mathrm{~b}$ shows the results obtained during the vegetation growing season. Both the plots indicate that, despite the simplifying assumption of a single soil layer, the proposed model well reproduces the observed trends.

However, owing to the hypothesis of homogeneous soil layer, the model fails at reproducing, especially at the shallowest investigated depths, the entity of the decrease of water potential observed immediately after the rainfall events (Fig. 6a).

In Fig. $6 \mathrm{~b}$ it can also be noted that, despite the introduced seasonal root water uptake module, the modelled suction at the shallowest depths is affected by rainfall events occurring during the flourishing vegetation period (in contrast with the experimental observations). A better result could probably be obtained if the unconstrained calibration of all the vegetation-related parameters was carried out.

It is worth noting that the values of the parameters allowing to achieve such results (even those which have been identified by calibration) are all in agreement with what expected
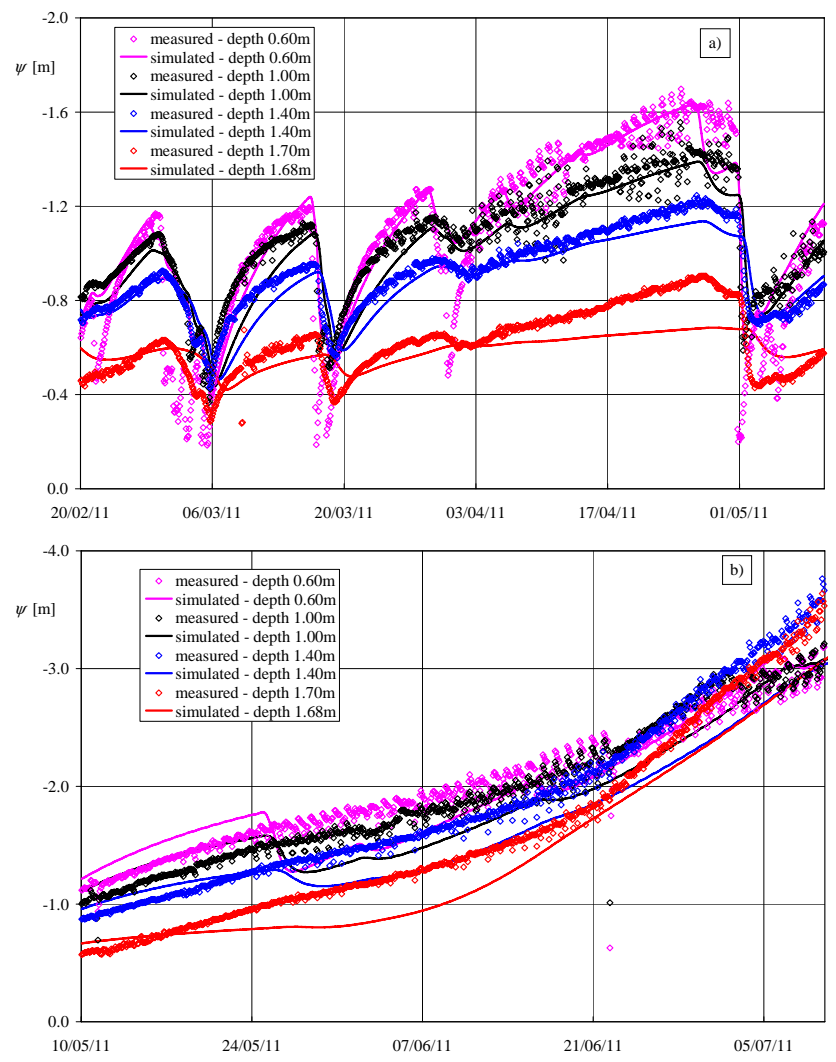

Fig. 6. Comparison between simulated and observed capillary pressure head at various depths during the period considered for model calibration: slope with leafless trees and low-developed underbrush (above); slope during the vegetation flourishing period (below).

either from the literature or from available information about the monitored site and the involved soil.

In particular, the water retention curve of the homogeneous soil cover simulating the behaviour of the more complex layered deposit, plotted in Fig. 4, is close to the experimental data observed in the layers deeper than $1.40 \mathrm{~m}$ below the soil surface, indicating that the behaviour of the layered profile is mainly determined by the finest layer. Furthermore, the hydraulic conductivity curve is in substantial agreement with the available data about unsaturated ashes of layer B (Fig. 5). At saturation, the effective value results one order of magnitude larger than those provided by the measurements carried out over undisturbed saturated samples collected at the investigated slope. However, this result was expected, as in the field soil saturated hydraulic conductivity is affected by the presence of large voids, such as macropores or structural voids, which are hardly detected within small specimens in laboratory. The high value of the exponent of the Brooks and Corey hydraulic conductivity function $(\delta=5.67)$, indicating that soil texture covers a wide range of void dimensions, confirms such interpretation.

Also the identified maximum canopy interception of precipitation, referred to the period of the year when the 
Table 3. Monthly mean climatic characteristics of Cervinara and corresponding estimated potential evapotranspiration fluxes.

\begin{tabular}{|c|c|c|c|c|c|}
\hline Month & $\begin{array}{r}\text { Mean } \\
\text { monthly } \\
\text { rainfall } \\
\text { height } \\
\text { [mm] }\end{array}$ & $\begin{array}{r}\text { Mean } \\
\text { monthly } \\
\text { minimum } \\
\text { temperature } \\
{\left[{ }^{\circ} \mathrm{C}\right]}\end{array}$ & $\begin{array}{r}\text { Mean } \\
\text { monthly } \\
\text { maximum } \\
\text { temperature } \\
{\left[{ }^{\circ} \mathrm{C}\right]}\end{array}$ & $\begin{array}{r}\text { Mean monthly } \\
\text { minimum } \\
\text { potential } \\
\text { evapotranspiration } \\
\text { rate }\left[\mathrm{mm} \mathrm{day}^{-1}\right]\end{array}$ & $\begin{array}{r}\text { Mean monthly } \\
\text { maximum } \\
\text { potential } \\
\text { evapotranspiration } \\
\text { rate }\left[\mathrm{mm} \mathrm{day}^{-1}\right]\end{array}$ \\
\hline January & 135 & 1.3 & 6.5 & 0.05 & 0.14 \\
\hline February & 150 & 1.1 & 6.8 & 0.05 & 0.15 \\
\hline March & 121 & 2.9 & 9.6 & 0.05 & 0.18 \\
\hline April & 109 & 5.5 & 12.9 & 0.06 & 0.22 \\
\hline May & 74 & 10.0 & 18.3 & 0.55 & 1.93 \\
\hline June & 46 & 13.5 & 22.2 & 0.69 & 2.40 \\
\hline July & 32 & 16.3 & 25.9 & 0.82 & 2.94 \\
\hline August & 47 & 16.2 & 25.7 & 0.81 & 2.91 \\
\hline September & 80 & 13.5 & 22.2 & 0.69 & 2.40 \\
\hline October & 115 & 9.9 & 17.4 & 0.08 & 0.28 \\
\hline November & 187 & 5.2 & 11.3 & 0.06 & 0.19 \\
\hline December & 163 & 2.7 & 7.9 & 0.05 & 0.16 \\
\hline
\end{tabular}

vegetation flourishes $\left(I_{\max }=4.0 \mathrm{~mm}\right)$, is in agreement with literature indications for deciduous woods (Breuer et al., 2003).

The linear reservoir model of the underlying aquifer, introduced as bottom boundary condition at the interface between soil cover and bedrock, does not mean to reproduce the actual water table fluctuations, about which no experimental information is available, but rather their effects upon the water potential at the bottom. However, the identified value of the time constant $K_{\mathrm{a}}$, multiplied times the assumed effective porosity $n_{\mathrm{a}}$ of the fractured limestone, produces a spring recession coefficient $\left(n_{\mathrm{a}} K_{\mathrm{a}}\right)^{-1} \cong 2.3 \times 10^{-1}$ days $^{-1}$ which is in close agreement with those estimated for temporary or seasonal springs draining small catchments in similar hydrogeological contexts (Petrella et al., 2009).

As already mentioned in Sect. 2, the data collected by the monitoring station during years 2010 and 2012 are similar to those of 2011. So, rather than validating the model against soil suction data measured during such periods, the calibrated model has been applied to the simulation of the behaviour of the soil cover during 1999, when, on the early morning of 16 December, a large flow-like landslide occurred at a location along the slope close to the monitoring station (Fig. 1a). The hourly rainfall data of the rain gauge of S. Martino Valle Caudina (BN), around $3.0 \mathrm{~km}$ northeast of the landslide location, have been used for the simulation. With a total yearly precipitation of $1803.6 \mathrm{~mm}, 1999$ has been the fourth most rainy year since 1969 . In particular, the rainfall amount between March and July was around $230 \mathrm{~mm}$ more than the long-term average, and during 14 and 15 December, a rainfall amount of more than $300 \mathrm{~mm}$ in $40 \mathrm{~h}$ was recorded.

Figure 7 reports the time history of capillary pressure head at various depths along the entire year 1999, as predicted by the model, together with the corresponding daily hyetograph.
It looks clear how, owing to the unusually rainy spring and early summer, capillary pressure head, especially in the upper $0.50 \mathrm{~m}$, stayed below $-5.0 \mathrm{~m}$ for most of the summer. Such unusual wet conditions at the end of summer caused a fast decrease of suction of the entire soil layer due to the precipitation that occurred in autumn (monthly rainfall heights between September and November resulted not far from the average values). Finally, the effects of the extreme rainfall event of 14 and 15 December were enhanced by the wetness of the soil profile at the beginning of the event, when capillary pressure head ranged between $-0.9 \mathrm{~m}$ and $-2.4 \mathrm{~m}$ along the entire soil cover (Fig. 8).

Figure 8 shows that during the rainfall event soil suction dropped down along the whole soil profile, and that, on 16 December around 05:00 a.m., it was below $0.2 \mathrm{~m}$ in the upper $1.50 \mathrm{~m}$, a condition never attained during all the performed simulations. Such values, in presence of other local conditions (e.g. a higher inclination, a scarp, a road cut, etc...), might lead to slope failure.

To better highlight the modelled effects of rainfall infiltration upon the equilibrium of the slope, the stability of the cover has been studied under the hypothesis of infinite slope. The safety factor, along a plane parallel to the ground surface, has been evaluated through the extension of the MohrCoulomb criterion to unsaturated soils (Fredlund and Rahardjo, 1993):

$F_{\mathrm{S}}=\frac{c^{\prime}+c(\psi)+\left(\sigma_{\alpha}-u_{a}\right) \cdot \tan \varphi^{\prime}}{\gamma \cdot d \cdot \sin \alpha \cdot \cos \alpha}$.

In Eq. (14) $c^{\prime}[\mathrm{Pa}]$ is the effective cohesion; $c(\psi)[\mathrm{Pa}]$ is the apparent cohesive intercept, i.e. the contribution of suction to shear strength; $\left(\sigma_{\alpha}-u_{a}\right)[\mathrm{Pa}]$ is the normal net stress along a plane parallel to the ground surface; $\gamma\left[\mathrm{N} \mathrm{m}^{-3}\right]$ is the unit weight of soil depending on water content; $d[\mathrm{~m}]$ is the depth 


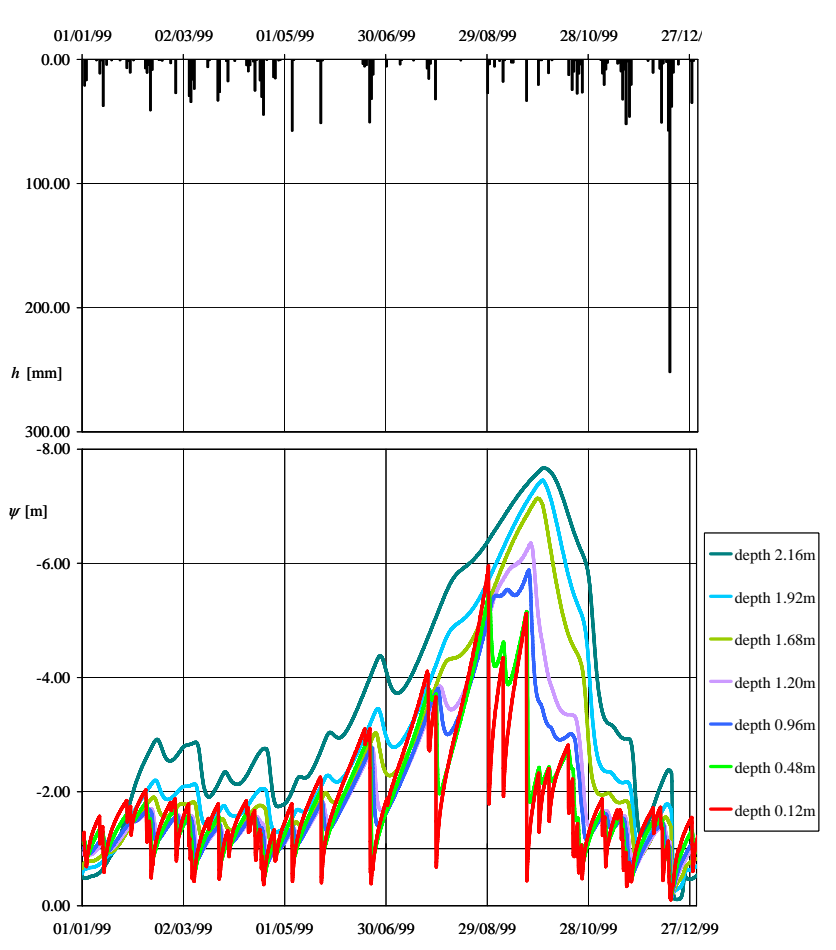

Fig. 7. Daily hyetograph (above) and simulated capillary pressure head at various depths (below) during 1999.

from the ground surface; $\alpha$ [rad] is the slope inclination angle.

The analysis has been carried out for the layered profile found at nest 2 of the monitoring station (Fig. 1c). The adopted shear strength properties of layers B and D are reported in Table 1; for both the layers, the apparent cohesion $c(\psi)$ has been evaluated by means of the experimental relationship obtained for the ashes by Olivares and Picarelli (2003). The topsoil has been characterised with the same parameters adopted for layer B.

Figure 9 reports the predicted trend of $F_{\mathrm{S}}$ at four depths during the event of December 1999. The obtained results indicate that, considering the mean inclination of the slope $\left(40^{\circ}\right)$, the upper part of the cover (up to a depth of $1.2 \mathrm{~m}$ ) approaches a failure condition between the 11:00 p.m. of the 15 December and the 05:00 a.m. of the 16th. Furthermore, as shown in Fig. 10, which reports the minimum predicted values of $F_{\mathrm{S}}$ for various slope inclinations, the failure could involve also the bottom of the soil cover at the steepest locations (with inclinations higher than $44^{\circ}$ ) along the slope.

As already pointed out above, the assumption of a single soil layer limits the capability of the model to reproduce the fastest soil suction reductions following rainfall events. Consequently, as shown in Fig. 9, the predicted reduction of safety factor at the depth of $-2.16 \mathrm{~m}$ is somewhat delayed. Nonetheless, the model is capable of adequately capturing the establishment of potential conditions of landslide triggering.

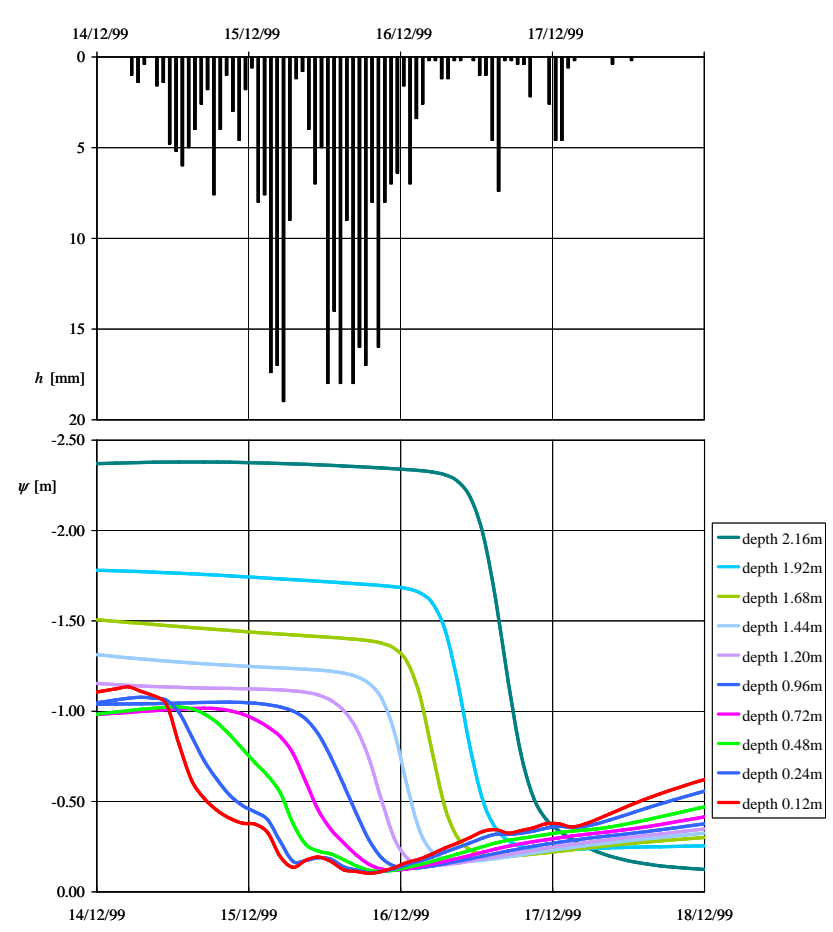

Fig. 8. Hourly hyetograph (above) and simulated capillary pressure head at various depths (below) during the rainfall event of 14 to 16 December, when a flow slide was triggered on the early morning of 16 December.

\section{Conclusions}

A simplified one-dimensional hydrological model of a slope covered with pyroclastic deposits is presented. The slope, with a fairly regular inclination of around $40^{\circ}$, is characterised by a layered cover of volcanic ashes and pumices, with thickness ranging between $1.8 \mathrm{~m}$ and $2.5 \mathrm{~m}$, laying upon a fractured limestone bedrock.

The main simplification of the proposed model consists in the introduction of a single homogeneous soil layer in place of the layered soil profile observed at the slope. Therefore, the hydraulic characteristic curves of such single layer cannot be experimentally derived, but have been obtained through model calibration against field data. To such aim, soil suction and volumetric water content have been measured with a time resolution of two hours at various locations and depths for more than two years. Besides, also hourly rainfall has been measured by means of a rain gauge installed at the same site. The identified parameters of the water retention curve were constrained in such a way that it resulted close to the available data of soil water content and suction observed in the field at various depths.

The data provided by field monitoring shed light also on other important features of the hydrological behaviour of the slope. In particular, soil suction and volumetric water content measured in the upper soil layers indicated that the seasonal variations of the vegetation cover significantly 


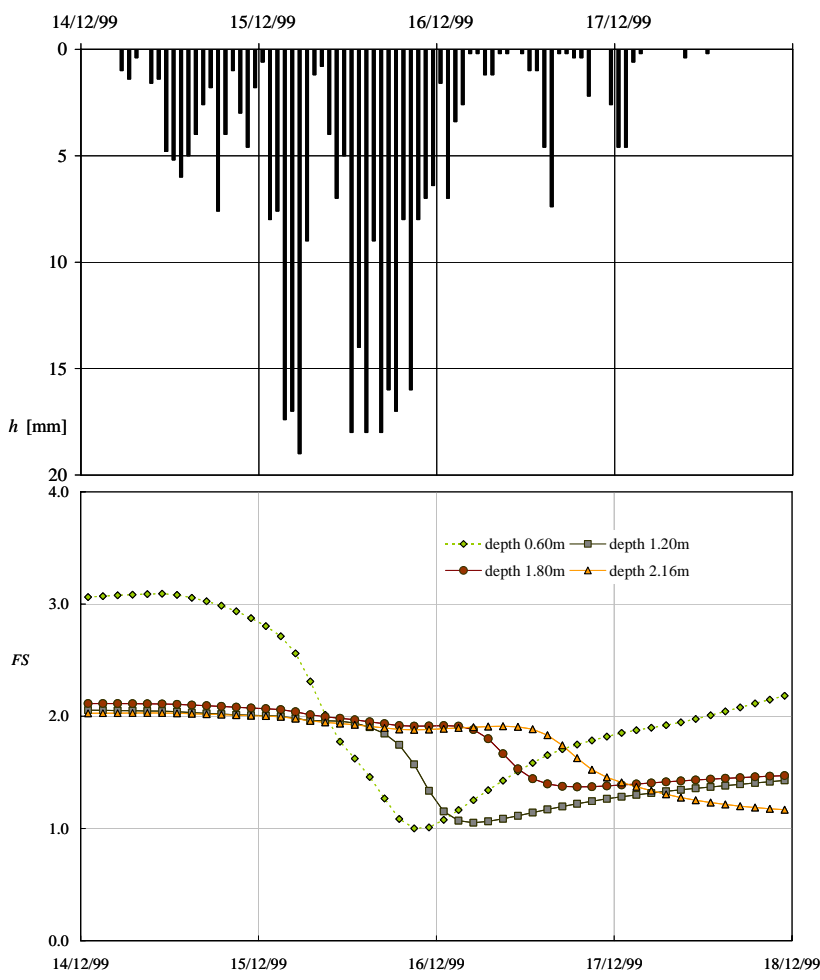

Fig. 9. Hourly hyetograph (above) and simulated trend of the safety factor at various depths (below) during the event of December 1999 evaluated for the mean slope inclination angle $\left(40^{\circ}\right)$. The safety factor has been evaluated with the limit equilibrium Eq. (14) under the hypothesis of infinite slope geometry.

affected infiltration and evapotranspiration processes, as well as canopy interception of precipitation: in fact, the slope is covered by deciduous chestnut woods that are leafless from October to April, and also a dense underbrush grows only during the late spring and summer. Therefore, the evapotranspiration has been introduced by means of a root water uptake model in which the parameters related to vegetation during the growing season have different values than from autumn to early spring. Also the canopy maximum interception assumes different values in the two periods.

The field monitoring data indicated that the soil cover was always drained from the bottom, and that the highest vertical downward water potential gradient occurred during the warm and dry season (from May to September). Such behaviour can be interpreted as the effect of the fluctuations of the water table of an aquifer laying in the fractured limestone bedrock. Therefore, a simple linear reservoir model has been introduced as a bottom boundary condition to link the water potential at the soil-bedrock interface with the fluctuations of the water table.

Despite the simplifying assumptions made, the model counts 27 parameters. However, the physical basis of the models of the various considered hydrological processes, allows the number of parameters to be limited to only 10 which

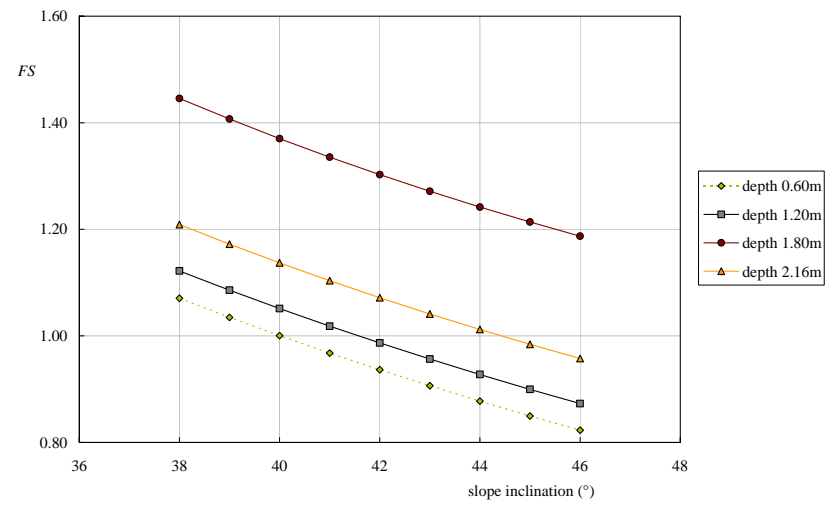

Fig. 10. Predicted minimum values of the safety factor at various depths during the event of December 1999 for different slope inclination angles.

have been identified through model calibration. Furthermore, also in the case of calibrated parameters, the availability of field monitoring data at high temporal resolution made possible to constrain the range of parameters variability in such a way to reduce possible problems of equifinality. This led to an approximate (but physically sound) solution of the inverse problem of parameter identification, well-posed in the Tikhonov sense (Tikhonov, 1963; Sun, 1994). In fact, an unconstrained calibration procedure could have led to overspecialisation of the model for the calibration set, hampering its general validity. Instead, the calibrated model has been successfully applied to the simulation of the hydrological response of the slope to the hourly precipitations occurred during 1999, when a large flow-like landslide occurred on the early morning of 16 December at a location along the slope close to the monitoring station. The safety factor of the slope, calculated with the values of soil suction predicted by the model, indicated that for inclinations higher than $44^{\circ}$, the entire soil cover attained failure conditions.

Therefore, despite the simplifying assumption of single soil layer, which hampers the capability of the model to correctly simulate the sharpest drops of soil suction, the proposed model can predict the potential establishment of landslide triggering conditions.

Acknowledgements. The presented results have been obtained thanks to the rainfall data kindly provided by the Centre for Meteorological Forecasting and Meteo-Hydro-Pluviometric and Landsides Monitoring of the Civil Protection Agency of Regione Campania.

Edited by: T. Bogaard 


\section{References}

Arnone, E., Noto, L. V., Lepore, C., and Bras, R. L.: Physicallybased and distributed approach to analyze rainfall-triggered landslides at watershed scale, Geomorphology, 133, 121-131, 2011.

Breuer, L., Eckhardt, K., and Frede, H.-G.: Plant parameter values for models in temperate climates, Ecol. Model., 169, 237-293, 2003.

Brooks, R. H. and Corey, A. T.: Hydraulic properties of porous media, Hydrology Papers, Colorado State University, 3, 1-25, 1964.

Capparelli, G. and Versace, P.: FLaIR and SUSHI: two mathematical models for early warning of landslides induced by rainfall, Landslides, 8, 67-79, 2010.

Cascini, L., Cuomo, S., and Guida, D.: Typical source areas of May 1998 flow-like mass movements in the Campania region, Southern Italy, Eng. Geol., 96, 107-125, 2008.

Cascini, L., Sorbino, G., Cuomo, S., and Ferlisi, S.: Seasonal effects of rainfall on the shallow pyroclastic deposits of the Camoania region (southern Italy), Landslides, online first, doi:10.1007/s10346-013-0395-3, 2013.

Celico, F., Petrella, E., and Celico, P.: Hydrogeological behaviour of some fault zones in a carbonate aquifer of Southern Italy: an experimentally based model, Terra Nova, 18, 308-313, 2006.

Crosta, G. B. and Dal Negro, P.: Observations and modelling of soil slip-debris flow initiation processes in pyroclastic deposits: the Sarno 1998 event, Nat. Hazards Earth Syst. Sci., 3, 53-69, doi:10.5194/nhess-3-53-2003, 2003.

Damiano, E., Olivares, L., and Picarelli, L.: Steep-slope monitoring in unsaturated pyroclastic soils, Eng. Geol., 137-138, 1-12, 2012.

Di Crescenzo, G. and Santo, A.: Debris slides-rapid earth flows in the carbonate massifs of the Campania region (Southern Italy): morphological and morphometric data for evaluating triggering susceptibility, Geomorphology, 66, 255-276, 2005.

Eriksson, H., Eklundh, L., Hall, K., and Lindroth, A.: Estimating LAI in deciduous forest stands, Agr. Forest Meteorol., 129, 2737, 2005.

Feddes, R. A., Kowalik, P., Kolinska-Malinka, K., and Zaradny, H.: Simulation of field water uptake by plants using a soil water dependent root extraction function, J. Hydrol., 31, 13-26, 1976.

Fredlund, D. G. and Rahardjo, H.: Soil Mechanics for Unsaturated Soils, in: Wiley-Interscience Publications, John Wiley \& Sons, Inc., 1993.

Goldberg, D. E.: Genetic algorithms in search, optimization and machine learning, Addison-Wesley, Reading, Massachussets, 1989.

Greco, R., Guida, A., Damiano, E., and Olivares, L.: Soil water content and suction monitoring in model slopes for shallow flowslides early warning applications, Phys. Chem. Earth, 35, 127-136, 2010.

Guadagno, F. M., Forte, R., Revellino, P., Fiorillo, F., and Focareta, M.: Some aspects of the initiation of debris avalanches in the Campania region: the role of morphological slope discontinuities and the development of failure, Geomorphology, 66, 237-254, 2005.

Guzzetti, F., Peruccacci, S., Rossi, M., and Stark, C. P.: Rainfall thresholds for the initiation of landslides in central and southern Europe, Meteorol. Atmos. Phys., 98, 239-267, 2007.

Herbst, M., Rosier, P. T. W., McNeil, D. D., Harding, R. J., and Gowing, D.: Seasonal variability of interception evaporation from the canopy of a mixed deciduous forest, Agr. Forest Meteorol., 148, 1655-1667, 2008.

Ivanov, V., Bras, R. L., and Vivoni, E. R.: Vegetation-Hydrology Dynamics in Complex Terrain of Semiarid Areas: II. EnergyWater Controls of Vegetation Spatio-Temporal Dynamics and Topographic Niches of Favorability, Water Resour. Res., 44, WR005588, doi:10.1029/2006WR005588, 2008a.

Ivanov, V. Y., Bras, R. L., and Vivoni, E. R.: Vegetation-Hydrology Dynamics in Complex Terrain of Semiarid Areas: I A Mechanistic Approach to Modeling Dynamic Feedbacks, Water Resour. Res., 44, WR005595, doi:10.1029/2006WR005595, 2008b.

Mancarella, D. and Simeone, V.: Capillary barrier effects in unsaturated layered soils, with special reference to the pyroclastic veneer of the Pizzo d'Alvano, Campania, Italy, Bull. Eng. Geol. Environ., 71, 791-801, 2012.

Mancarella, D., Doglioni, A., and Simeone, V.: On capillary barrier effects and debris slide triggering in unsaturated soil covers, Eng. Geol., 147-148, 14-27, 2012.

Montgomery, D. R. and Dietrich, W. E.: A physically based model for the topographic control on shallow landsliding, Water Resour. Res., 30, 1153-1171, 1994.

Muyzlo, A., Llorens, P., Valente, F., Keizer, J. J., Domingo, F., and Gash, J. H. C.: A review of rainfall interception modelling, J. Hydrol., 370, 191-206, 2009.

Netti, N., Damiano, E., Greco, R., Olivares, L., Savastano, V., and Mercogliano, P.: Natural Hazard Risk Management: a Multidisciplinary Approach to Define a Decision Support System for Shallow Rainfall-Induced Landslides, The Open Hydrology Journal, 6, 97-111, 2012.

Nyambayo, V. P. and Potts, D. M.: Numerical simulation of evapotranspiration using a root water uptake model, Comput. Geotech., 37, 175-186, 2010.

Olivares, L. and Picarelli, L.: Shallow flowslides triggered by intense rainfalls on natural slopes covered by loose unsaturated pyroclastic soils, Géotechnique, 53, 283-288, 2003.

Petrella, E., Capuano, P., and Celico, F.: Unusual behaviour of epikarst in the Acqua dei Faggi carbonate aquifer (Southern Italy), Terra Nova, 19, 82-88, 2007.

Petrella, E., Capuano, P., Carcione, M., and Celico, F.: A highaltitude temporary spring in a compartmentalized carbonate aquifer: the role of low-permeability faults and karst conduits, Hydrol. Process., 23, 3354-3364, 2009.

Regalado, C. M., Munoz Carena, R., Socorro, A. R., and Hernandez Moreno, J. M.: Time domain reflectometry models as a tool to understand the dielectric response of volcanic soils, Geoderma, 117, 313-330, 2003.

Rolandi, G., Bellucci, F., Heizler, M. T., Belkin, H. E., and De Vivo, B.: Tectonic controls on the genesis of ignimbrites from the Campanian Volcanic Zone, southern Italy, Miner. Petrol, 79, 3-31, 2003.

Rosso, R., Rulli, M. C., and Vannucchi, G.: A physically based model for the hydrologic control on shallow landsliding, Water Resour. Res., 42, W06410, doi:10.1029/2005WR004369, 2006.

Shuttleworth, W. J.: Evaporation, in: Handbook of Hydrology, edited by: Maidment, D., McGraw-Hill inc., New York, 4.14.40, 1993.

Sorbino, G. and Nicotera, M. V.: Unsaturated soil mechanics in rainfall-induced flow landslides, Eng. Geol., online first, doi:10.1016/j.enggeo.2012.10.008, 2013. 
Sun, N.-Z.: Inverse Problems in Groundwater Modeling, Kluwer Academic Publishers, Dordrecht, 1994.

Tikhonov, A. N.: Solution of ill-posed problems and the regularization method, Soviet Mathematics Doklady, 4, 1035-1038, 1963.

van Genuchten, M. T.: A closed-form equation for predicting the hydraulic conductivity of unsaturated soil, Soil Sci. Soc. Am. J. 44, 615-628, 1980.
Versace, P., Sirangelo, B., and Capparelli, G.: Forewarning model of landslides triggered by rainfall, in: Proceedings of 3rd International Conference on Debris-flow Hazards Mitigation: Mechanics, Prediction and Assessment, Davos, Switzerland, 2, 12331244, 2003.

Worthington, S. R. H. and Ford, D. C.: Self-Organized Permeability in Carbonate Aquifers, Ground Water, 47, 326-336, 2009. 